\title{
The behaviour of the long-latency stretch reflex in patients with Parkinson's disease
}

\author{
JC ROTHWELL, JA OBESO, MM TRAUB, CD MARSDEN \\ From the Department of Neurology, Institute of Psychiatry and King's College Hospital Medical School, \\ Denmark Hill, London
}

SUMMARY The size of the long-latency stretch reflex was measured in a proximal (triceps) and distal (flexor pollicis longus) muscle in 47 patients with Parkinson's disease, and was compared with that seen in a group of 12 age-matched normal control subjects. The patients were classified clinically into four groups according to the degree of rigidity at the elbow or tremor. Stretch reflexes were evaluated while the subject was exerting a small force against a constant preload supplied by a torque motor, and the size of the reflex response was measured as fractional increase over basal levels of activity. When stretches were given at random intervals by increasing the force exerted by the motor by a factor of 2 or 3 , there was a clear trend for the more severely affected patients to have larger long latency responses in the triceps muscle, although there was no change in the size of the short-latency, spinal component of the response. In contrast, there was no change in the size of the long-latency response of the flexor pollicis longus in any group of patients with Parkinson's disease. Despite any differences in reflex size, the inherent muscle stiffness of both muscles appeared to be normal in all groups of patients with Parkinson's disease, since the displacement trajectory of the limb following the force increase was the same as control values in the short $(25 \mathrm{~ms})$ period before reflex compensation could intervene. In 20 of the patients and in seven of the control subjects, servo-controlled, ramp positional disturbances were given to the thumb. Up to a velocity of $300 \%$, the size of the long-latency stretch reflex was proportional to the log velocity of stretch. This technique revealed, in both moderately and severely rigid patients, increases in the reflex sensitivity of the flexor pollicis longus, which had not been clear using step torque stretches alone. However, whether using ramp or step displacements, long latency stretch reflex gain was not closely related to rigidity; reflex size was within the normal range in many patients with severe rigidity. Enhanced long latency stretch reflexes thus contribute to, but may not be solely responsible for, rigidity in Parkinson's disease.

The muscular rigidity in Parkinson's disease is characterised clinically by a sustained increase in resistance to passive movement of a joint throughout its range. Walshe ${ }^{1}$ ascribed this rigidity to some over-reaction of the stretch reflex mechanism. He found that intramuscular injection of local anaesthetic sufficient to abolish the tendon jerk, while leaving motor power intact, considerably reduced the rigidity in patients with Parkinson's disease. Three years earlier, in 1921, Foerster ${ }^{2}$ also had noted a

Address for reprint requests: Prof $\mathrm{CD}$ Marsden, Institute of Psychiatry, De Crespigny Park, Denmark Hill, London SE5 8AF, UK.

Received 21 August 1982 and in revised form 14 October 1982 Accepted 18 October 1982 decrease in rigidity after surgical section of the dorsal roots in a number of patients. The proposed increase in stretch reflex excitability cannot be due to increased gamma drive to muscle spindles, since Burke, Hagbarth and Wallin, ${ }^{3}$ using direct intraneural recordings of spindle afferent fibres, have shown that the degree of alpha-gamma coactivation is normal in Parkinson's disease. Any small increase in the level of spindle discharge "at rest" was found to be consistent with the small amounts of alpha-motoneurone activity in patients who had difficulty in relaxing their muscles completely. They suggested that if the stretch reflex excitability is indeed enhanced in Parkinson's disease, the gain of the reflex arc must be increased at some central site.

The spinal monosynaptic pathway generally is 
considered to be normal in patients with Parkinson's disease, as judged by the size of the tendon jerk and of H-reflexes. Indeed, the most substantial reflex changes always have been noted to be in the static component of the muscle stretch response. ${ }^{4}$ Because of this it has been proposed that long loop stretch reflex pathways may be involved in the production of rigidity. The idea that long-latency stretch reflexes are increased in size in Parkinson's disease is attractive, since these responses are believed to use supraspinal pathways, separate from those of the tendon jerk. Such supraspinal systems might be expected to be preferentially affected in Parkinson's disease. These responses occur at approximately twice tendon jerk latency in the muscles of the human forearm, and may be much larger than the monosynaptic reflexes in the same muscles. ${ }^{5-7}$ They have been labelled as the M1 (tendon jerk) and the M2 (long-latency) response by some authors, and in the wrist flexors and biceps, they may be followed by a discrete M3 response in about $30 \%$ of normal subjects. $^{8}$

There has been a good deal of debate over the size of the long-latency responses in patients with Parkinson's disease. Lee and Tatton ${ }^{9}$ originally examined the long latency stretch reflexes in "relaxed" wrist flexor muscles. They observed a large increase in the size of the M2 response in patients with Parkinson's disease, while the spinal latency M1 response was unchanged. Non-rigid patients had normal long-latency responses. The size of the EMG response was quantified with respect to the preceding levels of activity in the muscle, since the size of the long-latency response is proportional to the level of background muscle contraction. ${ }^{57}$ Such normalisation is essential, because patients with Parkinson's disease cannot relax. In Tatton and Lee's experiment, ${ }^{\text {' }}$ subjects were instructed either not to react to the disturbance, or to oppose it as rapidly as possible. Mortimer and Webster ${ }^{10}$ studied the stretch reflex in the "relaxed" biceps muscle under the same conditions, and again found an increase in the size of the long-latency responses, which they correlated with a mechanical measure of the degree of elbow rigidity. However, if the subjects were instructed to maintain a constant position, or if there was any preload on the biceps muscle, this change in size of the stretch reflex was not seen. In constrast with these results, Evarts et al $^{11}$ evoked long-latency reflexes in biceps by rapid wrist supination while the subject was exerting a small pronating force. In these circumstances they could find no change in the size of biceps stretch reflex, if they took into account the generally increased levels of background muscle activity in their patients. This was confirmed by Dufresne,
Soechting and Tolosa ${ }^{12}$ again in biceps and triceps. In our own previous studies ${ }^{13}$ in the flexor pollicis longus, we stretched the muscle while the patient was exerting a small opposing force against an existing preload, and also failed to find any increase in the size of the long latency stretch reflex in Parkinson's disease.

We believe that many of the differences in these results arise through the different methods of investigation, different ways of measuring reflex size, and the use of a variety of muscle groups (see Marsden, Rothwell and Day ${ }^{14}$ ). The aim of the present experiments is to provide a complete description of the behaviour of the long latency stretch reflex in both proximal and distal muscles of the arm under standard conditions in a large group of patients with Parkinson's disease of varying severity.

\section{Methods}

We have examined the long latency stretch reflexes in flexor pollicis longus and triceps brachii, as representative examples of a distal and proximal arm muscle respectively. Triceps was chosen in preference to biceps (which has been used by most other investigators) because initial experiments showed the results to be more reliable and repeatable in triceps, and less dependent on the exact degree of wrist pronation/supination than in biceps.

The general methods have been described in detail before $^{7}$ and will only be mentioned briefly here. Constant torque disturbances were given to both muscles and, in addition, servo-controlled ramp position displacements were given to the thumb. In all the trials for flexor pollicis longus and triceps, the subject was asked not to interfere with the movement but to maintain a constant position by constant effort throughout the test. Since the torque or position disturbances only lasted $200 \mathrm{~ms}$, this usually proved to be quite easy.

\section{Flexor pollicis longus step torque disturbances}

The subject sat comfortably before a low inertia torque motor (Printed Motors G9M4H) with his thumb pad resting on a lever arm attached to the spindle of the motor. The thumb was clamped at the proximal phalanx, allowing movement only of the interphalangeal joint, which was flexed to about $10^{\circ}$. There was a small background torque in the motor of $0 \cdot 10 \mathrm{Nm}$ acting to extend the thumb, and the subject was required to maintain a constant thumb position with reference to a visual display on an oscilloscope screen before him. Two sizes of stretch referred to in the text as small and large disturbances were intermixed and given at random intervals between 4 and 5.5 seconds. The torque was increased by a factor of two $(0.2 \mathrm{Nm})$ or three $(0.3 \mathrm{Nm})$ for a period of $200 \mathrm{~ms}$ in $50 \%$ of trials at random, and visual feedback was removed for the duration of the disturbance. Control trials in which there was no increase in torque also were recorded. Thumb position was monitored from the output of a sensitive Bourns servopotentiometer mounted on the motor shaft. Surface EMGs were recorded from silver-silver chloride electrodes over 
the belly of the muscle, and were amplified by a Devices 3160 preamplifier with a time constant of $20 \mathrm{~ms}$, low pass filtered to attenuate the signal by $3 \mathrm{~dB}$ at $2.5 \mathrm{kHz}$. The signals were then amplified by a Devices 3120 amplifier and were rectified and integrated by a Devices Signal Processor type 4010. The experiment was controlled by a PDP 12 computer which sampled the data of thumb position, velocity and rectified and integrated EMG at $1 \mathrm{kHz}$ per channel over a $250 \mathrm{~ms}$ period starting $50 \mathrm{~ms}$ before each stretch. Averages of 24 or 32 trials were made in all with a rest of 5 min between each set of eight. Computer programs were written by $\mathrm{Mr} \mathrm{HB}$ Morton.

\section{Triceps step torque disturbances}

The subject sat with his forearm resting at shoulder height on a table before him. The elbow was flexed to $90^{\circ}$ so that the forearm was vertical, and a short chain was wrapped around the semipronated wrist and wound round a pulley on the spindle of a torque motor (Printed Motors G9M12). The motor was placed just above the shoulder pulling the elbow into flexion. A standing force of $8 \mathrm{~N}$ was exerted on the wrist, rising to $16 \mathrm{~N}$ for the small disturbances, and to $24 \mathrm{~N}$ for the large disturbances, for a period of $200 \mathrm{~ms}$, starting $50 \mathrm{~ms}$ into the recording sweep. EMGs were recorded from triceps using surface electrodes.

\section{Flexor pollicis longus ramp positional disturbances}

In these trials the motor was driven using a position servo driven power amplifier designed by Mr HC Bertoya. The subject pressed his thumb pad on a stiff lever with a torque of $0.10 \mathrm{Nm}$, using a visual display of thumb force as reference. Every 4 to $5.5 \mathrm{~s}$, the motor was displaced in a steadily increasing ramp of position lasting $200 \mathrm{~ms}$. Six velocities of ramp were used from $15 \%$ to $600 \%$, reaching a maximum displacement of $20^{\circ}$. Sets of trials were performed alternately with the three slowest and the three highest velocity ramps in each. Twenty-five per cent of each set of trials consisted of control run in which there was no change in motor position, and both the three different stretches and these control trials were interspersed at random. Averages of eight trials of each type were collected in each set, and a grand average made at the end of the test of 24 runs. The display of thumb torque was blanked during the disturbances.

\section{Measurement of records}

The size of the long latency stretch reflex was measured from the integrated EMG records over a time period which was determined from inspection of the rectified EMG. In triceps, the spinal latency component of the response also was measured in the same way in those subjects in whom it formed an obvious component of the response. Following the step torque stretches, the average timing of the long latency reflex in flexor pollicis longus was from $\mathbf{4 5} \mathrm{ms}$ to $96 \mathrm{~ms}$ after the disturbance; in triceps it was from $45 \mathrm{~ms}$ to $90 \mathrm{~ms}$ after the stretch. The spinal latency response occurred between 17 and $40 \mathrm{~ms}$ in the latter muscle. Similar timings were found for the fast ramp stretches in flexor pollicis longus, but the onset of the reflex was usually slightly later during the two slowest stretches. This was

\section{A: FPL}

P.D.
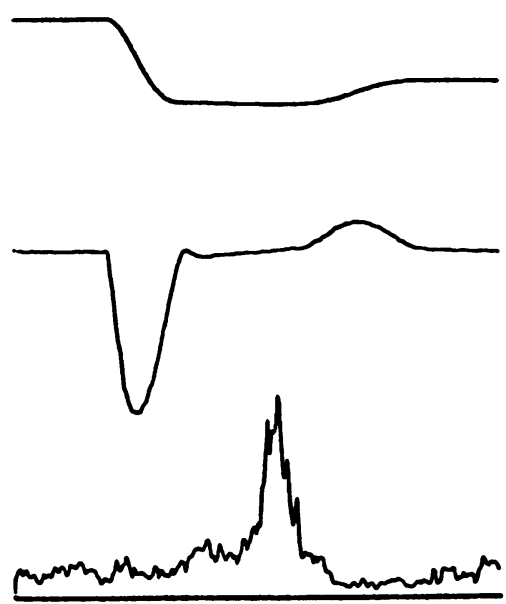
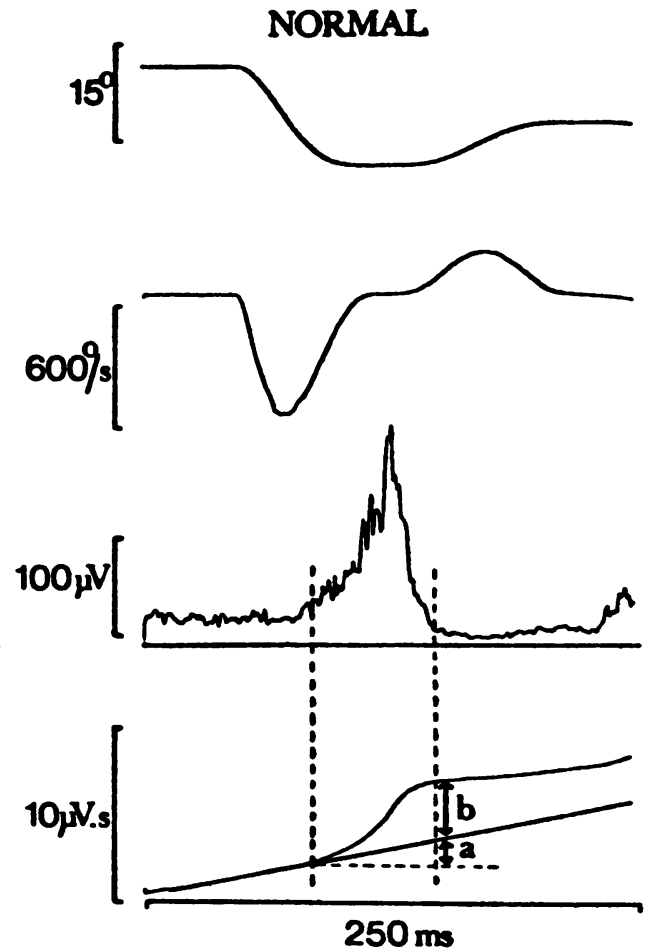


\section{B: TRICEPS}

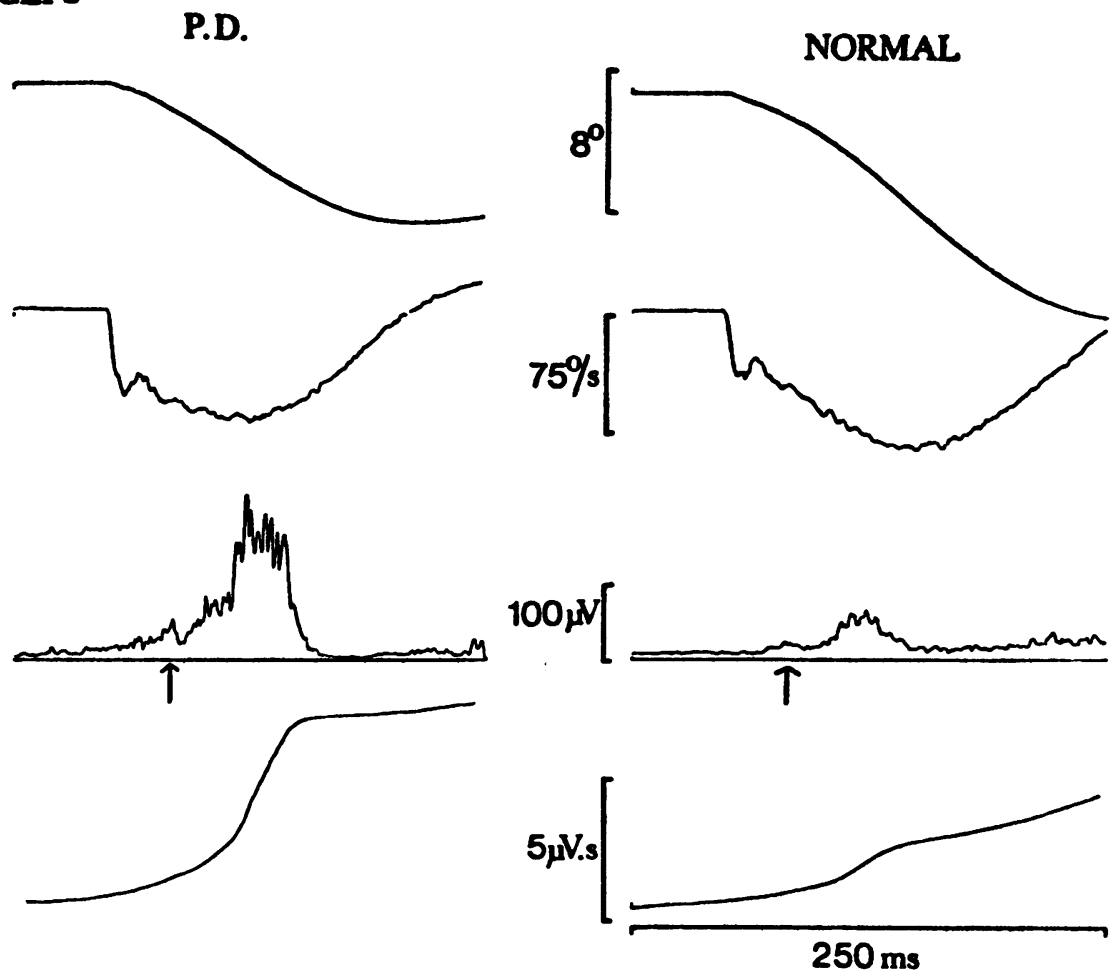

Fig 1 Stretch reflexes elicited in flexor pollicis longus $(A)$ and triceps $(B)$ following step torque disturbances in a representative normal individual (right) and a severely rigid patient with Parkinson's disease (PD, left). The standing torque exerted on the thumb was $0.10 \mathrm{Nm}$ and the standing force exerted on the wrist was $8 \mathrm{~N}$. In the examples illustrated, the force was increased by a factor of two $50 \mathrm{~ms}$ after the start of the recording sweep. Traces are from the top downwards: thumb or elbow position, velocity, rectified surface EMG with baseline from flexor pollics longus or triceps, and integrated EMG. The method of measurement of reflex EMG size is illustrated in the normal records from flexor pollicis longus. The start and finish of the reflex response was measured by eye from the rectified traces, and is indicated by the vertical dotted lines. The size of the response was measured from the integrated traces as the fractional increase over control levels of activity. This is the only diagram in which the control level of integrated EMG activity, recorded in trials in which no disturbance was given to the thumb, is illustrated. Spinal latency components of the response (which are not evident in this subject) were not measured in the long thumb flexor, although they were in the triceps, where they were more prominent (arrows in B). The size of the reflex response is approximately the same in the thumb of both subjects, whereas the triceps reflex is very much larger in the patient with Parkinson's disease.

Traces are the average of 24 trials each.

probably due to the soft thumb pad taking up the initial slow movement of the thumb lever before rotation of the joint began (see fig 3 ). The size of each response always was expressed as a percentage increase over control levels of activity in the same period (see fig 1).

The group data of stretch reflex size, following step torque disturbances, were not normally distributed and there was also a considerable difference in the spread of values from group to group. Because of this a KolmogorovSmirnov two-sided test was used to detect any group differences, and Spearman's rank correlation coefficient was calculated to determine whether there was any significant trend in the data values from group to group.
Subjects (table 1)

The patients were 47 outpatients from the King's College Hospital Parkinson's Disease Clinic, who gave informed consent to these tests. Twelve control, neurologically normal and age matched subjects were chosen from the hospital staff. The patients were studied while on their usual drug regime, so providing a wide spectrum of severity of the disorder. The rigidity of all patients was assessed clinically in the arm chosen for study by passive manipulation of the elbow joint while the subject tried to remain at rest. We also tried to assess the rigidity of the interphalangeal joint of the thumb in the same manner, but this proved difficult and unreliable because of the small range of 
Table 1 Details of patient groups used in the step and ramp torque experiments

\begin{tabular}{|c|c|c|}
\hline Group & Number & $\begin{array}{l}\text { Age (yr) } \\
\pm 1 S E\end{array}$ \\
\hline $\begin{array}{l}\text { Normal subjects } \\
\text { Parkinson's disease }\end{array}$ & 12 & $64 \pm 2$ \\
\hline $\begin{array}{l}\text { Tremor } \\
\text { Mild } \\
\text { Moderate } \\
\text { Severe }\end{array}$ & $\begin{array}{r}8 \\
17 \\
16 \\
6\end{array}$ & $\begin{array}{l}60 \pm 4 \cdot 8 \\
60 \cdot 5 \pm 2 \cdot 5 \\
60 \pm 2 \cdot 8 \\
59 \pm 3\end{array}$ \\
\hline
\end{tabular}

The patient's rigidity was scored clinically for the affected limb to be studied before the tests were carried out as described in Methods.

movement and the wide variation in the amount of subcutaneous fascia around the joint, which substantially increased the resistance to movement in well-built individuals. Elbow rigidity was scored on a scale from $0-3$, and the patients classified into 3 groups: (1) Mild (rigidity = 1), (2) Moderate (rigidity $=2$ ), and (3) Severe (rigidity $=3$ ). Tremulous patients, in whom it was impossible to determine rigidity with any accuracy were assigned to a separate (Tremor) group.

\section{Results}

\section{(A) STEP TORQUE DISTURBANCES}

Step torque disturbances of two sizes (large and small, see Methods) were given to the triceps and long flexor of the thumb in 47 patients with Parkinson's disease and in 12 neurologically normal, agematched controls (see table 1). Typical examples of stretch reflexes in each muscle from a normal subject and a patient in the severe group are shown in fig 1. As an indication of the similarity of limb trajectory in patient and normal groups, the maximum velocity of stretch was measured following the large disturbance, and also the position of the thumb or elbow 25 or $50 \mathrm{~ms}$ after onset of stretch. The data is summarised in table 2. There was no difference in the trajectory of stretch in the normal group as compared to any of the patient groups, except for a small decrease in the amount of triceps stretch measured $50 \mathrm{~ms}$ after the torque increase in severely affected patients. Thus at least over the first $25 \mathrm{~ms}$ of the stretch, during which no reflex events can intervene, the intrinsic muscle stiffness of triceps and the long thumb flexor was approximately the same in patients with Parkinson's disease as in normal individuals.

The sizes of the stretch reflexes in both muscles are shown graphically for all subjects in fig 2 . The spinal latency component of the stretch reflex was quite easily measured in triceps, but often it was not present in the flexor pollicis longus and, therefore, was excluded from the data. In triceps, the spinal component showed little change in size in any of the patient groups (fig 2A), in confirmation of the results of Lee and Tatton' on wrist flexors and of Mortimer and Webster ${ }^{10}$ on biceps. In contrast, the long-latency component in triceps was increased in size in many of the patients with Parkinson's disease (fig $2 \mathrm{~B}, \mathrm{C})$. Comparison of the group of data showed that the stretch reflexes of the moderately affected patients were increased in size over control data following the large stretch (mean increase of $152 \%$; $p<0.05$ ). However, no other individual group comparisons were significant. Nevertheless, if the group of tremulous patients were omitted, there was a clear trend for the more severely affected patients to have large stretch reflexes (Spearman's $\rho$ $=0.3821, \mathrm{p}<0.01$ for the large stretches; $\rho=$ $0.281, p<0.05$ for the small stretches). In flexor pollicis longus there was no consistent change in the size of the long latency response in any group compared to the control subjects (fig $2 \mathrm{D}, \mathrm{E}$ ). The duration of the long latency stretch reflex was the same in all groups of subjects, and unchanged from normal values (50 ms for the FPL, $45 \mathrm{~ms}$ for triceps).

The total group data is presented in fig 2 to show the large degree of variability in stretch reflex size from subject to subject within each group. The degree of overlap between groups was large and even in triceps, where the average data (fig $2 \mathrm{C}$ ) showed a difference between moderate group and normals, there were still a large number of patients who were clinically rigid but who nevertheless had responses whose size was in the normal range. Similarly, there were some patients with only mild rigidity who had long latency stretch reflexes which were much larger than any normal individuals. We will return to this point in the discussion.

Table 2 Similarity of stretch trajectory between patient and normal groups after step torque disturbances

\begin{tabular}{|c|c|c|c|c|c|c|}
\hline Group & $V \max \mathrm{deg} / \mathrm{s}$ & Thumb $P_{25}$ deg & $P_{\text {so }}$ deg & $V \max \mathrm{deg} / \mathrm{s}$ & Elbow $P_{2 s}$ deg & $P_{s 0}$ deg \\
\hline $\begin{array}{l}\text { Normals (12) } \\
\text { Parkinson's disease }\end{array}$ & $810 \pm 65$ & $15.0 \pm 0.8$ & $26 \pm 3.0$ & $104 \pm 9$ & $1.30 \pm 0.06$ & $3.2 \pm 0.14$ \\
\hline $\begin{array}{l}\text { Tremor (8) } \\
\text { Mild (17) } \\
\text { Moderate (16) } \\
\text { Severe (6) }\end{array}$ & $\begin{array}{l}870 \pm 61 \\
835 \pm 53 \\
845 \pm 60 \\
900 \pm 26\end{array}$ & $\begin{array}{l}15 \cdot 0 \pm 1 \cdot 0 \\
14 \cdot 0 \pm 0 \cdot 7 \\
14 \cdot 8 \pm 0 \cdot 9 \\
15 \cdot 8 \pm 0 \cdot 5\end{array}$ & $\begin{array}{l}27 \pm 2 \cdot 8 \\
25 \pm 2 \cdot 0 \\
29 \pm 3 \cdot 5 \\
28 \pm 2 \cdot 2\end{array}$ & $\begin{array}{r}102 \pm 10 \\
91 \pm 10 \\
99 \pm 9 \\
106 \pm 15 .\end{array}$ & $\begin{array}{l}1.25 \pm 0.07 \\
1.38 \pm 0.27 \\
1.30 \pm 0.04 \\
1.14 \pm 0.04^{*}\end{array}$ & $\begin{array}{l}3 \cdot 0 \pm 0 \cdot 15 \\
2 \cdot 8 \pm 0 \cdot 15 \\
3 \cdot 2 \pm 0 \cdot 14 \\
2.7 \pm 0 \cdot 11\end{array}$ \\
\hline
\end{tabular}

Maximum stretch velocity $(\mathrm{Vmax})$ and limb position $25 \mathrm{~ms}\left(\mathrm{P}_{25}\right)$ and $50 \mathrm{~ms}\left(\mathrm{P}_{50}\right)$ following the large torque disturbance to flexor pollicis longus (Thumb) and triceps (Elbow) in all groups of subjects (number in parentheses). Means \pm 1 SE are given. ${ }^{*} p<0.05$, compared to the normal group by Student's $t$ test. 


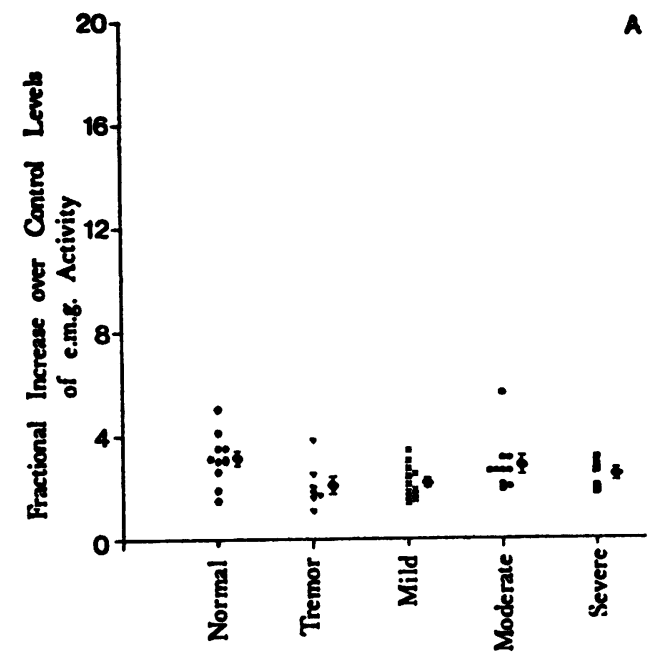

Fig 2 Sizes of the stretch reflexes produced by step torque disturbances in triceps $(A, B, C)$ and flexor pollicis longus $(D, E)$ plotted for all subjects. In triceps, the spinal-latency component of the response was measured following the large disturbance $(A)$, whereas the long-latency component was measured following both the small $(B)$, the large $(C)$ disturbance. In the flexor pollicis longus only the long-latency component was measured after the small $(D)$ and large disturbances $(E)$. Each data point has been plotted for the subjects in all five groups, with the average $\pm 1 S E$ on the right of each. Two labelled points in $C$ are not plotted to scale. More details in text.

TRICEPS
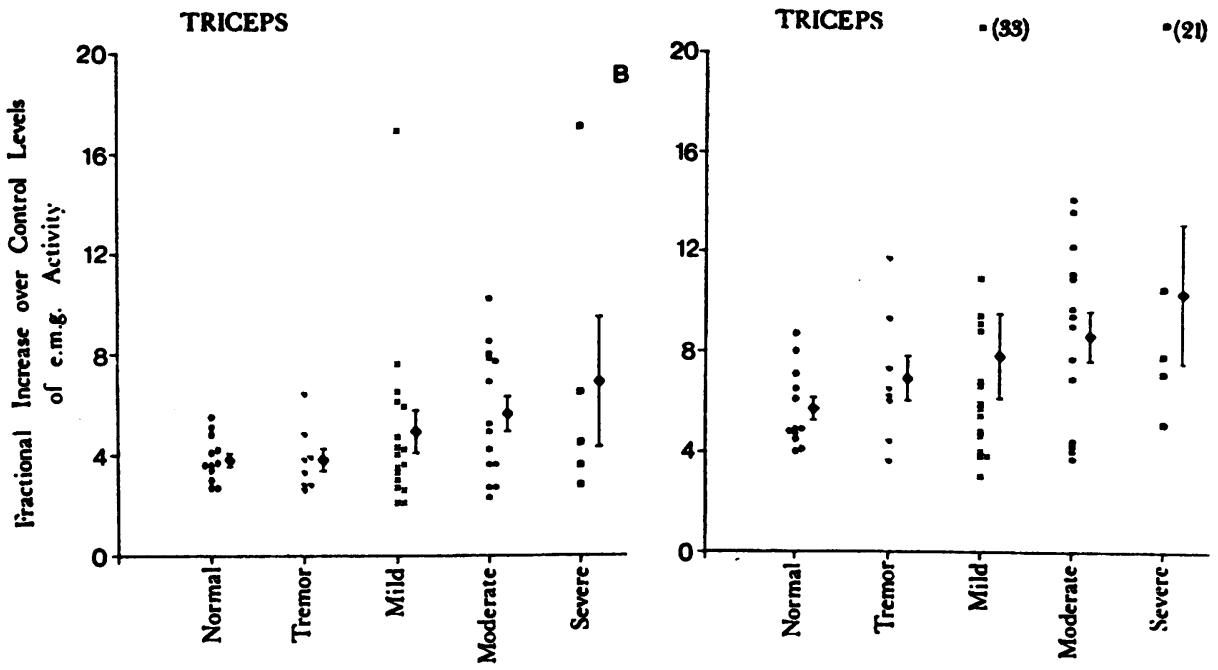

FPL

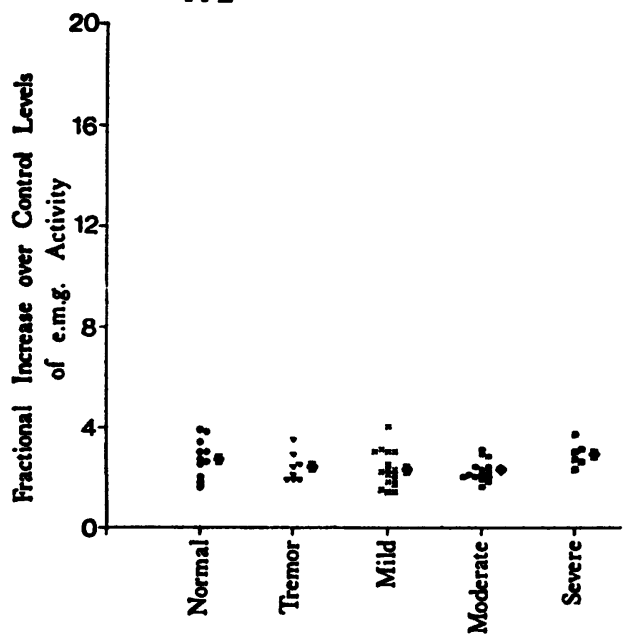

FPL

D

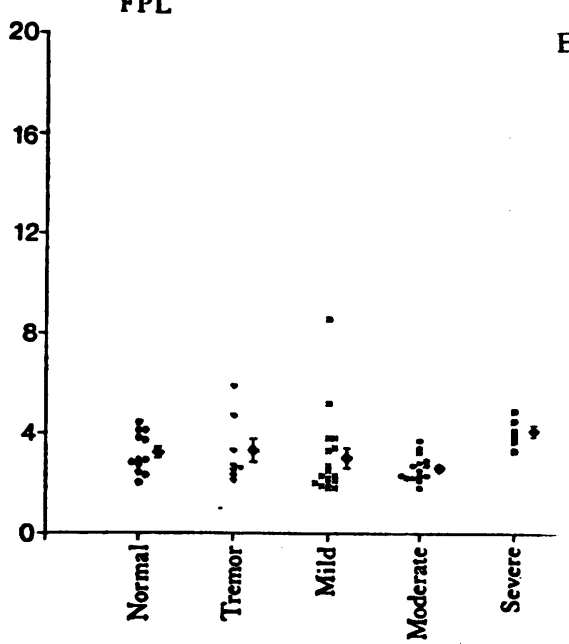

E 
(B) RAMP POSITIONAL DISTURBANCES

In addition to the constant torque disturbances, we gave servo-controlled ramp displacements of the thumb to seven normal age-matched subjects and to 12 of the moderate and eight of the severe patients with Parkinson's disease. This type of stretch proved to be a more sensitive indicator of changes in reflex size in the flexor pollicis longus. A typical set of reflex responses from a normal individual and a patient from the severely rigid group are shown together in fig 3 , and the combined results from a group of moderate and severe patients are illustrated graphically in fig 4 for comparison with control values. In normal subjects and those with Parkinson's disease, increasing the velocity of the ramp produced larger and larger reflexes until saturation occurred at velocities greater than $300 \%$ s (fig 4A). However, it must be noted that at this velocity of
P.D.

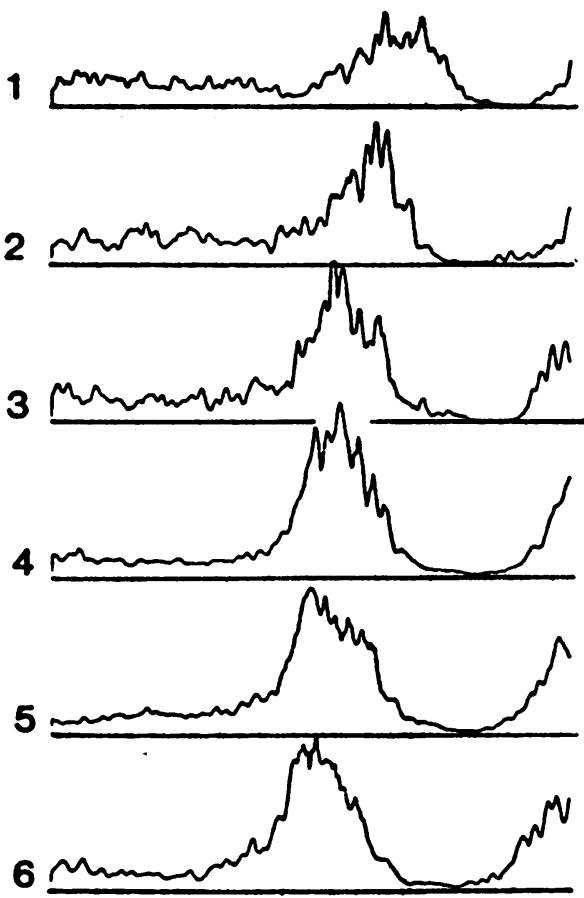

NORMAL
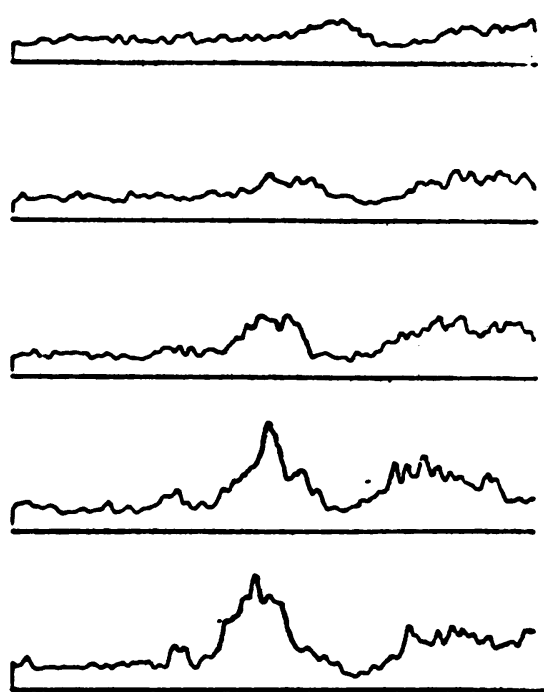

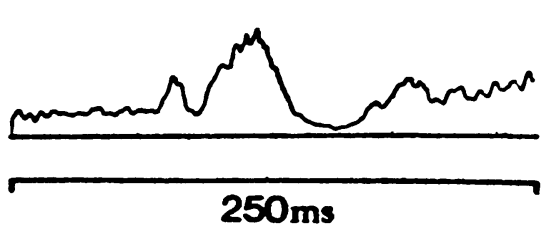

Fig 3 Reflex responses in flexor pollicis longus following servo-controlled ramp positional disturbances to the thumb in a representative normal subject (right) and a severely rigid patient with Parkinson's disease (PD, left). Traces are superimposed thumb position records (top, centre) and the corresponding surface rectified EMG responses with baseline from the flexor pollicis longus (below). The reflexes from the patient with Parkinson's disease clearly are much larger at all velocities of stretch. 

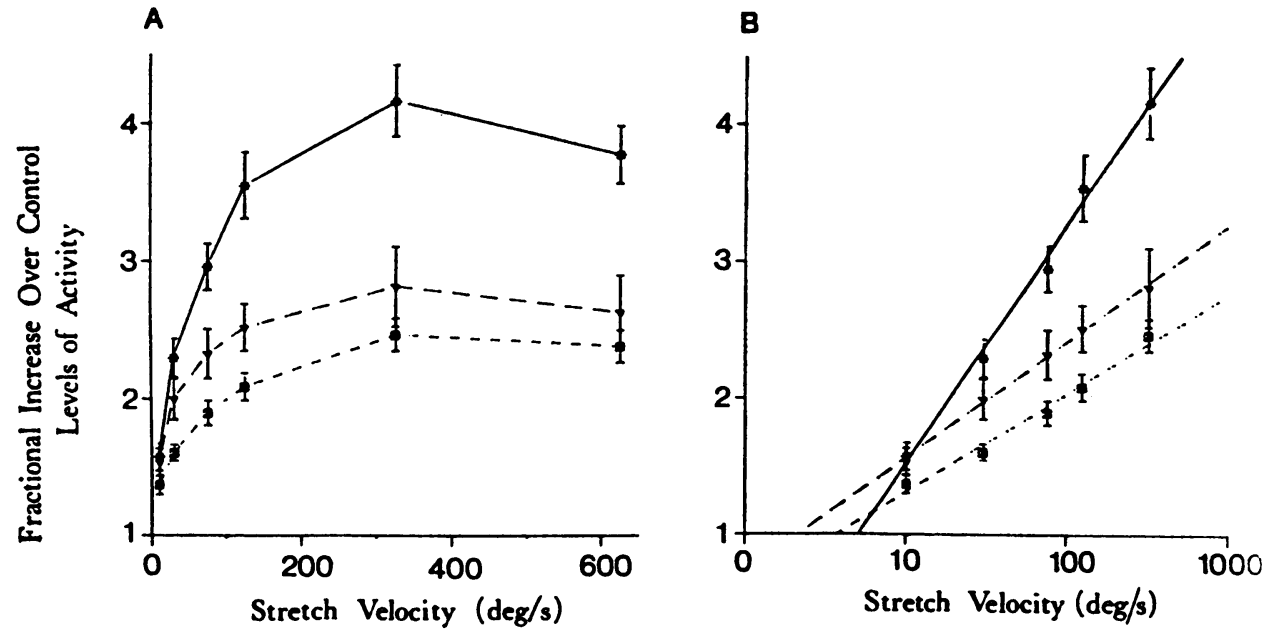

Fig 4 Relationship between stretch velocity and average size of the long-latency stretch reflex in flexor pollicis longus in 7 age-matched normal subjects (filled squares), 12 moderately rigid (inverted triangles) and 8 severely rigid (stars) patients with Parkinson's disease. The graph in $A$ has a linear $x$-axis, whereas that in $B$ has a logarithmic $x$-axis. The same data $( \pm$ $1 S E)$ is plotted in both graphs except that in $B$ the last saturated data point, at maximum stretch velocity, has been omitted in each group. Least squares linear regression lines have been fitted to the remaining points. The slopes are: normals, $0.73 \pm$ 0.06 (SE); moderate, $0.85 \pm 0.03$; severe, $1.75 \pm 0.08$. There is no significant difference between the $x$-intercepts of each group, although the slope of the line describing the severe group data is steeper $(p<0.05)$ than that of both the control and the moderately rigid group.

stretch, a $20^{\circ}$ displacement is complete within $66 \mathrm{~ms}$, which is some $30 \mathrm{~ms}$ before the end of the stretch reflex EMG response. Saturation above $300 \%$ s therefore may be due simply to failure of the stimulus to outlast the response, rather than to any saturation of physiological mechanisms. In fig 4B the first five points of this data, up to stretch velocities of $350 \%$, omitting the saturated last point, have been plotted after logarithmic transformation. The differences between the normal subjects and those with moderate and severe Parkinson's disease are emphasised.

The graphs show that in the group of severely affected patients with Parkinson's disease, there were two factors affecting the long latency reflex in the thumb. The gain of the response was increased such that the slope of the relationship between stretch velocity and reflex size was steeper, and also there was an increase in the EMG level at which the reflex saturated.

\section{Discussion}

The present results illustrate two points concerning the rigidity of Parkinson's disease. Firstly, the inherent muscle stiffness of activated muscle was the same as that of normal subjects over the short 25$50 \mathrm{~ms}$ period of stretch before nervous reflexes could operate. Thus, unlike the studies of Dietz et $\mathrm{al}^{15}$ on the muscles of the leg, we could find no evidence for any fundamental changes in mechanical properties of arm muscles which would contribute to the stiffness of patients with Parkinson's disease. Secondly, under certain conditions, the average size of the long latency EMG responses to muscle stretch, in groups of patients with Parkinson's disease, was proportional to the degree of clinicallyevaluated rigidity. The short latency spinal responses were unaffected. What, then, is responsible for the difference in the results reported in the literature over the past eight years, and the difference in our own results on the long thumb flexor when we test the stretch reflex in different ways?

From the controversies in the literature surrounding the size of the stretch reflex in Parkinson's disease there can be no doubt that different ways of examining these long latency responses can lead to different values of their sensitivity to muscle stretch. There are three main parameters which can affect the size of the recorded EMG responses to stretches of equal amplitude:

(1) THE BACKGROUND LEVEL OF EMG ACTIVITY IMMEDIATELY PRECEDING THE DISTURBANCE The absolute magnitude of the stretch reflex is directly proportional, over a wide range, to the tonic 
level of muscle activation. ${ }^{6}$ Because of this it is essential to normalise the size of the reflex response in terms of the preceding EMG activity. If the subject initially has a relaxed muscle, then in the absence of any ongoing EMG activity, it is impossible to determine the exact level of motoneurone excitability since subthreshold variations cannot be detected. Because of this we chose to have the subjects exert a small background force in the present experiments.

\section{(2) SATURATION OF THE RESPONSE}

As in any other system, it is important to test the responses in the range below their limit of saturation. We have shown previously in our studies on the long flexor of the thumb that the size of the long latency stretch reflex saturates for disturbances less than the maximum set by the limits of joint rotation. ${ }^{16}$ Thus, if the reflex saturated at the same level in patients as in controls, it would not be possible to demonstrate changes in reflex size in Parkinson's disease if the disturbances used to test the response were too large. However, in most of the other previously published studies of patients with Parkinson's disease, it has not been clear whether any reported increases in reflex size have been a result of increases in the level of saturation of the response, or increases in its sensitivity.

\section{(3) THE RATE OF STRETCH}

The exact trajectory of the stretch to the final end position should be carefully controlled. Although the long latency EMG responses are thought to be produced by afferent input occurring in the first 0-20 ms of muscle stretch, they interact at the level of the alpha-motoneurones with spinal reflexes produced by afferent input generated much later in the stretch. ${ }^{17-19}$ In Sherringtonian terms, this may be envisaged as an interaction between phasic and tonic components of the reflex response, with the maintained input from stretched receptors in muscle contributing a tonic excitation to the motoneurone pool. Thus for strict comparisons to be made between groups, the whole time course of muscle stretch must be similar for up to $20 \mathrm{~ms}$ before the end of the long latency response. Because of this, we believe that servo-controlled positional displacements should prove a much more sensitive indicator of changes in stretch reflex size than step torque changes.

We suggest that failure to take into account one, or a combination of these points when comparing the results between different groups of workers has led to some of the discrepancies summarised above. Indeed, the data presented here on the stretch reflex of the long thumb flexor show how testing the reflex size by two different methods can lead to quite different results. Thus, when we used step torque disturbances to stretch the muscle, we found no change in the size of the long latency reflex. Using ramp stretches with a range of different velocities, the differences between groups became clearer. The curve describing the relationship between stretch velocity and reflex size was elevated above normal for both severely and moderately affected patients. Interestingly, analysis of either of the two fastest ramp stretches alone showed that the reflex size recorded in the moderately affected group was no different to that of the normal controls. The two step torque stretches used previously, had maximum velocities within this range and therefore this may partially explain why no consistent change in reflex size was observed using this technique. Another difference was that in the slower ramps, stretch of the muscle was continued throughout the whole period of the measured reflex response, whereas in the fastest ramp and in both the torque steps, the dynamic phase of stretching was complete well before the end of the stretch reflex response. The enhanced long latency reflexes seen in Parkinson's disease, therefore, may be most easily revealed when superimposed on a maintained tonic input from the lengthening muscle.

The ramp stretches allow for a more detailed description of stretch reflex behaviour than a series of step torque tests. They have shown, for the first time, that the size of the response is a direct function of the log velocity of the stretch, at least up to about $300-350 \%$ s. Above this velocity, stretches of prolonged duration cannot be given because of the physical limits of the joint rotation at the thumb, and hence we cannot say from this data whether the reflex sensitivity truly saturates at higher stretch velocities or whether the saturation is merely a functional consequence of early termination of the stretch. We do not have motors with enough power to produce servo-controlled displacements of the elbow, so that we could not perform the same series of ramp stretches with triceps. However, because of the large inertia of the forearm compared with the thumb, the profile of the triceps stretch produced by a step torque increment resembles a ramp displacement (see fig 1), and perhaps this is why the differences between Parkinsonian and normal stretch reflexes were revealed so clearly in such large proximal muscles.

In summary, we have shown that changes in the intrinsic muscle stiffness, at least in the early part of a stretch, cannot be responsible for the rigidity of Parkinson's disease, and that increases in clinical rigidity at the elbow joint may be correlated with increases in the size of long latency stretch reflexes 
in both proximal and distal muscles. Unfortunately, it is not possible to conclude with certainty that exaggeration of the sensitivity of the long latency stretch reflex pathway is by itself responsible for the muscular rigidity of Parkinson's disease. Many individual patients had reflexes which did not behave like the average responses of their group. For example, three of the five severely affected patients had triceps reflexes whose size was within the range of the normal control group, whereas one patient who was only mildly affected by the disease, had the largest stretch reflexes that we recorded. Human variability in the clinical assessment of rigidity perhaps may explain some of the exceptions but, clearly, there may be some other factors, which we have not analysed here; which can contribute to Parkinsonian rigidity. For example, in a clinical environment it is not possible, without EMG electrodes, to be certain that patients are totally relaxed, and the inability of many patients to achieve this may contribute substantially to the apparent rigidity of joints during passive movement. The rates of muscle stretch used in clinical manipulation also may be slower than those in the step torque disturbances used here. Thus, over long periods, the late polysynaptic reflexes from cutaneous afferents, which are known to be enhanced in Parkinson's disease,$^{20}$ also may contribute to increased muscle stiffness. At present we have not obtained enough detailed data to enable us to separate out these individual contributions. However, the average group results suggest that, when evaluated using servocontrolled positional displacements, stretch reflex size may be a useful objective physiological measure of Parkinsonian rigidity.

Thanks are due particularly to Mr HC Bertoya for designing the motor control servo system, and $\mathrm{Mr} \mathrm{R}$ Miller for building and maintaining the equipment used in these experiments. This work was supported by the Medical Research Council.

\section{References}

${ }^{1}$ Walshe FMR. Observations on the nature of the muscular rigidity of paralysis agintans, and its relationship to tremor. Brain 1924;47:159-77.

${ }^{2}$ Foerster O. Zur Analyse und Pathophysiologie der striaren Bewegungstorungen. Zeitschr fd ges Neurol $u$ Psychait 1921;73:1-21.

${ }^{3}$ Burke R, Hagarth K-E, Wallin BG. Reflex mechanisms in parkinsonian rigidity. Scand $J$ Rehab Med 1977;9:15-23.

4 Andrews CJ, Burke D, Lance JW. The response to muscle stretch and shortening in parkinsonian rigidity. Brain 1972;95:795-812.
${ }^{5}$ Marsden CD, Merton PA, Morton HB. Servo action in human voluntary movement. Nature 1972;238:140-3.

${ }^{6}$ Marsden CD, Merton PA, Morton HB. Is the human stretch reflex cortical rather than spinal? Lancet 1973;i:759-61.

${ }^{7}$ Marsden CD, Merton PA, Morton HB. Servo action in the human thumb. J Physiol (Lond) 1976;257:1-44.

${ }^{8}$ Lee RG, Tatton WG. Long loop reflexes in man: Clinical applications. In: Desmedt JE, ed. Cerebral Motor Control in Man: Long Loop Mechanisms. Prog Clin Neurophysiol Vol. 4. Basel: Karger, 1978;320-33.

${ }^{9}$ Lee RG, Tatton WG. Motor responses to sudden limb displacements in primates with specific CNS lesions and in human patients with motor system disorders. Can J Neurol Sci 1975;2:285-93.

${ }^{10}$ Mortimer JA, Webster DD. Relationships between quantative measures of rigidity and tremor and the electromyographic responses to load perturbations in unselected normal subjects and Parkinson patients. In: Desmedt JE, ed. Cerebral Motor Control in Man: Long Loop Mechanisms. Prog Clin Neurophysiol. Vol. 4. Basel: Karger, 1978:342-60

${ }^{11}$ Evarts EV, Teravainen HT, Beuchert DE, Calne DB. Pathophysiology of motor performance in Parkinson's disease. In: Calne DB, Fuxe K, eds. Dopaminerigc Ergot Derivatives and Motor Functions. Oxford: Pergamon Press, 1979:45-59.

${ }^{12}$ Dufresne JR, Soechting JF, Tolosa ES. Myotatic reflexes and the on-off effect in patients with Parkinson's disease. J Neurol Neurosurg Psychiatry 1981;44: 315-22.

${ }^{13}$ Marsden CD, Merton PA, Morton HB, Adam J. The effect of lesions of the central nervous system on long-latency stretch reflexes in the human thumb. In: Desmedt JE, ed. Cerebral Motor Control in Man: Long Loop Mechanisms Prog Clin Neurophysiol Vol. 4. Basel: Karger, 1978:334-41.

${ }^{14}$ Marsden CD, Rothwell JC, Day BL. Long-latency automatic responses to muscle stretch in man: their origins and their functions. In: Desmedt JE, ed. Motor Control Mechanisms in Man. Recent Progress and Clinical Applications. New York: Raven Press (in press).

${ }^{15}$ Dietz V, Quintern J, Berger W. Electrophysiological studies of gait in spasticity and rigidity. Brain 1981;104:431-49.

${ }^{16}$ Marsden CD, Merton PA, Morton HB, Rothwell JC, Traub MM. Reliability and efficacy of the long-latency stretch reflex in the human thumb. $J$ Physiol. 1981;316:47-60.

${ }^{17}$ Adam J. Human long-latency stretch reflexes. PhD thesis, 1976, London University.

${ }^{18}$ Lee RG, Tatton WG. Long-latency reflexes to imposed displacements of the human wrist: dependence or duration of movement. Exp Brain Res 1982;45:20716.

19 Vilis T, Cooke JD. Modulation of the functional stretch reflex by the segmental reflex pathway. Exp Brain Res 1976;25:247-54.

${ }^{20}$ Delwaide PJ, Schwab RS, Young RR. Polysynaptic spinal reflexes in Parkinson's disease. Neurology (Minneap) 1974;24:820-7. 